\title{
Analysis to the clinical characteristics and prognosis of MDA5 positive patients with dermatomyositis
}

\section{Yiying Yang}

Xiangya Hospital Central South University

Xiaoxia Zuo

Xiangya Hospital Central South University

Huali Zhang

Central South University Xiangya School of Medicine

Hui Luo

Xiangya Hospital Central South University

Sijia Liu ( $\square$ celialiu@csu.edu.cn )

Central South University Xiangya School of Medicine

\section{Research}

Keywords: dermatomyositis(DM), anti-MDA5 antibody, clinical manifestations, prognosis

Posted Date: June 2nd, 2020

DOI: https://doi.org/10.21203/rs.3.rs-29691/v1

License: (c) (1) This work is licensed under a Creative Commons Attribution 4.0 International License. Read Full License 


\section{Abstract}

Background: To explore the relationship between anti-MDA5 antibody and clinical manifestations of dermatomyositis(DM) and to explain the correlation of prognosis as well.

Methods: Retrospective analysis was performed at the Department of Rheumatology and Immunology in Xiangya Hospital, Central South University from April 2017 to February 2019. The clinical data were collected from 109 patients with DM, and then the patients were divided into anti-MDA5 antibody positive group and negative group according to the results of antibody detection, after which statistical analysis was carried out with SPSS 23.0 software.

Results: Among the 109 DM patients, the ratio of male to female is $1: 2.3$, with 58 positive anti-MDA5 antibody and 51 negative anti-MDA5 antibody. There is no difference in gender and age between the two groups, and patients with positive anti-MDA5 have a shorter course. The incidence of clinical symptoms, including Gottron sign, skin ulcer, joint pain, joint swelling, nail erythema, dyspnea, and cough in patients with anti-MDA5-positive DM is significantly higher than those in the anti-MDA5-negative group. AntiMDA5 antibodies are inversely associated with tumorigenesis. Patients with anti-MDA5-positive DM have less elevation of muscle enzymes and are prone to ILD and RPILD, while patients with anti-MDA5-positive DM have a high mortality rate and poor prognosis.

Conclusion: Combined with RP-ILD, the prognosis of DM is poor. When patients have these clinical manifestations and positive MDA5, they must actively undergo lung imaging examination and be alert to RP-ILD.

\section{Background}

As a heterogeneous diffuse connective tissue disease, idiopathic inflammatory myopathy(IIM) is characterized by muscle fatigue, chronic muscle weakness, and skeletal muscle mononuclear cell infiltration[1-3]. Subtypes of IIM are divided into dermatomyositis(DM), polymyositis(PM), inclusion body myositis(IBM), and immune-mediated necrotizing myositis(IMNM)[4]. Clinically, DM and PM are most

common. The incidence of IIM is low, and the annual incidence rate is about 1.16 19/million people ${ }^{[5]}$, with high mortality rate and poor prognosis[6-8]. The onset age has two peak periods, $10-15$ years old and 45-60 years old, and the average age of onset is 40-60 years old[9]. At present, the pathogenesis of IIM is still unclear, but previous studies have suggested that both immune and non-immune mechanisms are involved in its pathogenesis[10], especially cellular immune abnormalities and humoral immune abnormalities[11].

DM refers to the appearance of skin damage based on the clinical features of PM. In addition to muscle and skin involvement, commonly the respiratory system also involved in DM. Patients with DM have various manifestations of pulmonary involvement, with interstitial lung disease (ILD) being the most common one. ILD is also the common complication and the cause of death of patients with DM/PM[12]. 
The anti-melanoma differentiation-associated gene 5(MDA5) antibody is a 140,000 polypeptide that was first discovered in 2005 by Sato[13] through immunoprecipitation in the serum of some patients with clinical amyopathic dermatomyositis(CADM)-associated interstitial lung disease. In 2009, Sato screened with cDNA libraries and found that the cytoplasmic RNA helicase encoded by MDA5 is the target antigen of CADM-140 antibody[14]. Related studies[15] have indicated that in Asian countries, for adult patients with DM, the positive rate of anti-MDA5 antibody can reach from $20 \%$ to $50 \%$, but in Europe and the United States adults, the rate is only $5 \%$ to $10 \%$. Numerous studies have manifested that[16-18], antiMDA5 antibodies are closely related to DM and are of great value to the diagnosis of CADM. Some investigators have analyzed the risk factors of death in patients with $\mathrm{DM}$ and ILD ${ }^{[15]}$ and known that antiMDA5 antibody is an independent risk factor, and patients with DM and positive MDA5 antibody die from ILD. The survival time is less than 6 months, indicating that anti-MDA5 antibody plays a very important role in the prognosis of DM patients complicated with ILD.

In recent years, there has been an increasing number of studies on anti-MDA5 antibodies of DM and CADM $[19,20]$.Patients with anti-MDA5 antibody-positive DM are more prone to pulmonary interstitial changes that can result in respiratory failure. The mortality of patients with anti-MDA5 antibody-positive DM is high. The pathogenesis and related factors affecting prognosis are still unclear, And there is no relevant diagnosis and treatment guideline. Therefore, this study aims to analyze the clinical features and prognosis of anti-MDA5 antibody-positive DM patients in our hospital during the past 2 years, and to provide guidance for future diagnosis and treatment.

\section{Materials And Methods}

From April 2017 to February 2019, patients with DM were admitted to the Department of Rheumatology and Immunology in Xiangya Hospital, Central South University, and they met the Bohan-Peter's classification criteria of DM in 1975. Patients with other autoimmune diseases and children under the age of 14 were excluded.

The patient's serum was collected, and the myositis antibody test was completed. According to the test results, the patients were divided into two groups: anti-MDA5 antibody positive group and anti-MDA5 antibody negative group.

Clinical data, laboratory findings, combined pulmonary interstitial lesions, treatment options, and prognosis were collected from the two groups. Statistical analysis of the data was conducted by using SPSS 23.0. When $P<0.05$, it was defined as statistically significant.

\section{Results}

A total of 109 patients with DM were enrolled in this study. The ratio of male to female was 1:2.3, with 58 positive anti-MDA5 antibody and 51 negative MDA5 antibody(Table 1).The difference about disease duration between the two groups was statistically significance. 
Table 1. General conditions of patients

\begin{tabular}{cccc}
\hline & Anti-MDA5 antibody positive group $\llbracket \mathrm{n}=58 \square$ & Anti-MDA5 antibody negative group $\llbracket \mathrm{n}=51 \square$ & $\mathrm{P}$ \\
\hline Gender( male / female) & $15 \llbracket 43$ & $18 \square 33$ & 0.285 \\
Age & $48.33 \pm 12.02$ & $50.80 \pm 14.63$ & 0.334 \\
Age of onset & $48.10 \pm 12.12$ & $49.78 \pm 15.39$ & 0.525 \\
Disease duration(month) & $3.5 \square 2,6.25 \square$ & $6 \square 3,16 \square$ & $0.003^{*}$ \\
\hline
\end{tabular}

Note: $* \mathrm{P}<0.05$, the difference is statistically significant

In terms of clinical manifestations, the incidence of clinical symptoms, including Gottron sign, skin ulcer, joint pain, joint swelling, nail erythema, dyspnea, and cough in patients with anti-MDA5 antibody positive group was greatly higher than those in anti-MDA5 antibody negative group, and the two groups had significance. In the V-shaped shawl sign, the incidence of anti-MDA5 positive group was lower than that of anti-MDA5 negative group, and there was statistically significant(Table 2).

Table 2. Clinical manifestations of patients

\begin{tabular}{|c|c|c|c|}
\hline Clinical manifestations & Anti-MDA5 antibody positive group $\square \mathrm{n}=58 \square$ & Anti-MDA5 antibody negative group $\llbracket \mathrm{n}=51 \square$ & $\mathrm{P}$ \\
\hline Fever & $10(17.24 \%)$ & $5(9.80 \%)$ & 0.261 \\
\hline Heliotrope rash & $36(62.06 \%)$ & $30(58.82 \%)$ & 0.729 \\
\hline V-shaped shawl sign & $28(48.28 \%)$ & $35(68.63 \%)$ & $0.032 *$ \\
\hline Gottron sign & $47(81.03 \%)$ & $26(50.98 \%)$ & $0.001^{*}$ \\
\hline Holster sign & $2(3.45 \%)$ & $2(3.92 \%)$ & 0.896 \\
\hline Mechanic's hand & $6(10.34 \%)$ & $4(7.84 \%)$ & 0.652 \\
\hline Skin ulcer & $13(22.41 \%)$ & $5(9.80 \%)$ & $0.036^{*}$ \\
\hline Joint pain & $29(50 \%)$ & $7(13.73 \%)$ & $0.000^{*}$ \\
\hline Joint swelling & $18(31.03 \%)$ & $5(9.80 \%)$ & 0.007 \\
\hline Perlungual erythematosus & $9(15.51 \%)$ & $1(1.76 \%)$ & $0.014^{*}$ \\
\hline Dysphagia & $13(22.41 \%)$ & $15(29.41 \%)$ & 0.404 \\
\hline Choking & $1(1.72 \%)$ & 0 & 0.346 \\
\hline Dyspnea & $28(48.28 \%)$ & $11(21.56 \%)$ & $0.004^{*}$ \\
\hline Cough & $25(43.10 \%)$ & $10(19.61 \%)$ & $0.009^{*}$ \\
\hline Expectoration & $15(25.86 \%)$ & $7(13.73 \%)$ & 0.115 \\
\hline Amyosthenia & $40(68.97 \%)$ & $32(62.75 \%)$ & 0.494 \\
\hline Pulmonary arterial hypertension & 0 & $1(1.96 \%)$ & 0.462 \\
\hline
\end{tabular}

Note: $* \mathrm{P}<0.05$, the difference is statistically significant

IIM was more likely to be associated with pulmonary interstitial lesions. The difference in ILD and rapidly progressive interstitial lung disease(RPILD) between the two groups was statistically significant(Table 3). 
Table 3. Combined pulmonary interstitial lesions

\begin{tabular}{ccccc}
\hline & Total $\square \mathrm{n}=109 \square$ & Anti-MDA5 antibody positive group $\llbracket \mathrm{n}=58 \square$ & Anti-MDA5 antibody negative group $\square \mathrm{n}=51 \square$ & $\mathrm{P}$ \\
\hline ILD & $63(57.80 \%)$ & $47(81.03 \%)$ & $16(31.37 \%)$ & $0.000^{*}$ \\
RP-ILD & $9(8.26 \%)$ & $9(15.51 \%)$ & 0 & $0.003^{*}$ \\
\hline
\end{tabular}

Note: ${ }^{*} \mathrm{P}<0.05$, the difference is statistically significant

The liver function of the two groups was analyzed(Table 4),from which it was clearly found that there was no significant difference in serum total protein, albumin and globulin levels between the two groups, and there was a statistically significant difference in the levels of alanine aminotransferase(ALT) and aspartate aminotransferase(AST).

Table 4. Liver function analysis of anti-MD5 antibody positive group and anti-MDA5 antibody negative group

\begin{tabular}{|c|c|c|c|}
\hline & Anti-MDA5 antibody positive group $\llbracket \mathrm{n}=58 \square$ & Anti-MDA5 antibody negative group $\llbracket \mathrm{n}=51 \square$ & $\mathrm{P}$ \\
\hline Serum total protein $\square \mathrm{g} / \mathrm{L} \square$ & $63.72 \pm 7.42$ & $63.50 \pm 7.20$ & 0.874 \\
\hline Albumin $\square \mathrm{g} / \mathrm{L} \square$ & $31.95 \pm 5.67$ & $33.77 \pm 5.55$ & 0.094 \\
\hline Globulin $\square / \mathrm{L} \square$ & $31.77 \pm 5.75$ & $29.73 \pm 6.55$ & 0.085 \\
\hline $\mathrm{ALT} \square \mathrm{U} / \mathrm{L} \square$ & $46.6 \square 28.2,85.25 \square$ & $29.6 \square 19.5,52.8 \square$ & $0.005^{*}$ \\
\hline $\mathrm{AST} \square \mathrm{U} / \mathrm{L} \square$ & $67.5 \square 41.2,112.7 \square$ & $47.4 \llbracket 29.1,106.7 \square$ & $0.028^{*}$ \\
\hline
\end{tabular}

Note: $* \mathrm{P}<0.05$, the difference is statistically significant

The myocardial enzymology spectra in the two groups was analyzed and the differences among creatine kinase(CK), creatine kinase isoenzyme(CK-MB) and myoglobin(Mb) were statistically significant(Table 5).

Table 5. Analysis of muscle enzyme results in anti-MD5 antibody positive group and anti-MDA5 antibody negative group

\begin{tabular}{|c|c|c|c|}
\hline & Anti-MDA5 antibody positive group $\llbracket n=58 \square$ & Anti-MDA5 antibody negative group $\llbracket n=51 \square$ & $\mathrm{P}$ \\
\hline Lactate dehydrogenase $[\mathrm{U} / \mathrm{L} \square$ & $406.14 \pm 191.31$ & $429.56 \pm 270.94$ & 0.600 \\
\hline $\mathrm{CK} \square \mathrm{U} / \mathrm{L} \square$ & $70.45 \square 32.43,207.98 \square$ & $247.8 \square 98.15,1744.4 \square$ & $0.000^{*}$ \\
\hline CK-MB $\square \mathrm{U} / \mathrm{L} \square$ & $18.8 \square 16.45,24.08 \square$ & $28.05 \square 18.58,47.48 \square$ & $0.002^{*}$ \\
\hline $\mathrm{Mb} \square \mathrm{U} / \mathrm{L} \square$ & $30.5 \square 19.9,64.88 \square$ & $111.6 \square 42.15,331.05 \square$ & $0.000^{*}$ \\
\hline
\end{tabular}

Note: $* \mathrm{P}<0.05$, the difference is statistically significant

Analysis of the combination of other myositis antibodies between the two groups found that there was a statistically significant difference between the two groups in the anti-TIF1Y, anti-NXP2, anti-Ro-52 antibody positive(Table 6). 
Table 6. Anti-MD5 antibody positive group negative combination with anti-MDA5 antibody and other myositis antibody analysis

\begin{tabular}{|c|c|c|c|}
\hline & Anti-MDA5 antibody positive group $\square \mathrm{n}=58 \square$ & Anti-MDA5 antibody negative group $\square \mathrm{n}=51 \square$ & $\mathrm{P}$ \\
\hline Anti-Mi-2 $\alpha \square+\square$ & $1(1.72 \%)$ & $3(5.88 \%)$ & 0.249 \\
\hline 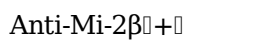 & $8(13.79 \%)$ & $4(7.84 \%)$ & 0.322 \\
\hline Anti-TIF1 $\gamma \square+\square$ & $5(8.62 \%)$ & $20(39.22 \%)$ & $0.000^{*}$ \\
\hline Anti-NXP2 $2+\square$ & $1(1.72 \%)$ & $8(15.69 \%)$ & $0.008^{*}$ \\
\hline Anti-SAE1 $+\square$ & $4(6.89 \%)$ & $3(5.88 \%)$ & 0.829 \\
\hline Anti-Ku$\square+\square$ & $3(5.17 \%)$ & $2(3.92 \%)$ & 0.755 \\
\hline Anti-PM-Scl100 $+\square$ & $1(1.72 \%)$ & $2(3.92 \%)$ & 0.484 \\
\hline 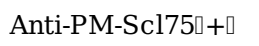 & $5(8.62 \%)$ & $5(9.80 \%)$ & 0.831 \\
\hline Anti-Jo- $1 \square+\square$ & $1(1.72 \%)$ & $3(5.88 \%)$ & 0.249 \\
\hline Anti-SRP $\square+\square$ & $4(6.89 \%)$ & $2(3.92 \%)$ & 0.497 \\
\hline 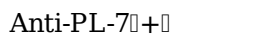 & $1(1.72 \%)$ & $4(7.84 \%)$ & 0.128 \\
\hline Anti-PL-12 $+\square$ & $1(1.72 \%)$ & $2(3.92 \%)$ & 0.484 \\
\hline Anti-EJ $\square+\square$ & $2(3.45 \%)$ & $3(5.88 \%)$ & 0.544 \\
\hline Anti-OJ $\square+\square$ & $1(1.72 \%)$ & 0 & 0.346 \\
\hline Anti-Ro-52₫+ם & $40(68.97 \%)$ & $19(37.25 \%)$ & $0.001^{*}$ \\
\hline
\end{tabular}

Note: $* \mathrm{P}<0.05$, the difference is statistically significant

According to analysis of the two groups combined tumors, it was discovered that the difference was statistically significant(Table 7).

Table 7. Combined tumor analysis

Anti-MDA5 antibody positive group $\llbracket \mathrm{n}=58 \square \quad$ Anti-MDA5 antibody negative group $\llbracket \mathrm{n}=51 \square \quad \mathrm{P}$

\begin{tabular}{llll}
\hline Number of combined tumors & 2 & 8 & - \\
Composition ratio & $3.45 \%$ & $15.69 \%$ & $0.027 *$ \\
\hline
\end{tabular}

Note: $* \mathrm{P}<0.05$, the difference is statistically significant

All patients followed up until April 2020 an observation cut-off point, and 16 of the 109 patients missed. Among the 58 patients with anti-MDA5 antibody-positive DM (Table 8), 30 of them displayed improved signals (51.72\%), with a stable condition, regular reduction in treatment, and without recurrence or aggravation. A total of 8 patients repeated (13.79\%). 11 dead during hospitalization, with $18.97 \%$ mortality rate and the prognosis was poor. As the 51 patients with anti-MDA5 antibody-negative DM, 35 patients improved a lot (68.63\%), with stable condition, regularly reduced during treatment, and without recurrence or aggravation. A total of 8 patients had repeated illnesses (15.69\%), and there was one death 
during hospitalization, with $1.96 \%$ fatality rate and poor prognosis. The difference in mortality between the two groups was statistically significant.

In terms of further analysis to poor prognosis for patients with MDA5 antibody-positive DM and RPILD for patients with stable/repetitive group (Table 9), 8 patients with poor prognosis were found to have RPILD, while in the stable/repetitive group, only 1 patient was with RPILD, showing a statistically significance between the two groups in the combined RPILD.

\begin{tabular}{|c|c|c|c|}
\hline & Anti-MDA5 antibody positive group $\llbracket n=49 \square$ & Anti-MDA5 antibody negative group $\llbracket \mathrm{n}=44 \square$ & $\mathrm{P}$ \\
\hline Stable condition & $30(61.22 \%)$ & $35(79.55 \%)$ & 0.073 \\
\hline Repeated condition & $8(16.33 \%)$ & $8(18.18 \%)$ & 0.767 \\
\hline Poor prognosis & $11(22.45 \%)$ & $1(2.27 \%)$ & $0.005^{*}$ \\
\hline
\end{tabular}

Note: $* \mathrm{P}<0.05$, the difference is statistically significant

Table 9. Comparison of RP-ILD differences in anti-MD5 antibody positive group

\begin{tabular}{llll}
\hline & the poor prognosis group $\llbracket \mathrm{n}=11 \square$ & the stable/repetitive group $\llbracket \mathrm{n}=38 \square$ & $\mathrm{P}$ \\
\hline Combined RP-ILD cases & 8 & 1 & - \\
Composition ratio & $72.72 \%$ & $2.63 \%$ & $0.000^{*}$ \\
\hline
\end{tabular}

Note: $* \mathrm{P}<0.05$, the difference is statistically significant

\section{Discussion}

Patients with anti-MDA5 antibody-positive DM have various clinical manifestations, and the severity is different. Some patients with atypical clinical manifestations are often missed or misdiagnosed, and patients with anti-MDA5 antibody-positive DM are more common with ILD or RPILD with high mortality rate and poor prognosis. Therefore, it is especially important to have a good knowledge of the clinical features for anti-MDA5 antibody-positive DM.

According to the results of an epidemiological survey made by Hiroyuki Tomimitsu[21] in Japan in 2016 to $17,000 \mathrm{DM}$ patients, the male/female ratio was about $1: 2.7$, and the majority of patients has an onset age between 40 and 60 years old. Among the 109 patients included in the study, the total male/female ratio was 1:2.3, and the onset age of anti-MDA5 antibody-positive group and antibody-negative group was approximately 40-60 years old with Japanese flow. The results were consistent. There was no difference in age, onset age, and gender between the two groups. There were 58 patients with anti-MDA5 antibody-positive DM, and the positive rate was $53.21 \%$, being consistent with Wang Kaige[15]. By analyzing the subtypes of patients with MDA5 antibody-positive DM, only one patient with clinical myositis dermatomyositis was found to be inconsistent with the literature[15], and the fact might be that only inpatient information was collected in this study. Some outpatients or patients in other departments 
such as Dermatology had incomplete information collection, so leading to certain selection bias. It was found that the difference in disease duration between the two groups was obvious. Patients with antiMDA5 antibody-positive DM had a shorter course of disease, which may be related to the rapid progression of the disease and the severity of the disease for patients with positive MDA5 antibody.

Common skin lesions of DM have Gottron sign, Heliotrope rash, V-shaped shawl sign, holster sign, technician hand, skin ulcer, and nail erythema, which are heterogeneous for each patient. The Gottron sign refers to the rash that occurs on the lateral side of the joint. In this study, patients with anti-MDA5 antibody-positive DM tended to have the Gottron sign, met with reports made by Li[18], but the pathogenesis of the Gottron sign have not yet been clearly illustrated. Whether there is correlation between them or not, a larger amount of samples are needed. The incidence of pruritus is common for DM patients. The incidence of Heliotrope rash in this study is $60.55 \%$, which conforms to Kazandjieva's reports[22]. The V-shaped sign marks the V-shaped erythematous rash in the anterior and upper chest, while the shawl sign shows a change in the skin of the scalp, shoulder and upper back. Sun[23] uncovered the negative correlation between V-shaped sign and the occurrence of ILD. The study conducted by $\mathrm{Wu}[24]$ showed that the shawl sign is irrelevant to the occurrence of ILD. However, this study revealed that patients with anti-MDA5-positive DM had fewer V-type shawl signs, which accords with Sun's findings. However, whether the V-shaped shawl sign is indeed negatively correlated with antiMDA5 antibody requires numerous data to further confirm. It is not common for DM patients to suffer from skin ulcers. In this study, there were 18 patients with skin ulcers (13.53\%), same with the reported incidence of 3-19\% by Narang[25]. So, DM patients with skin ulcers should be highly alert to whether they have anti-MDA5 antibody-positive and pulmonary interstitial lesions, and should regularly screen for myositis antibody and lung high-resolution CT. Perlungual erythematosus is often neglected in DM and fewer studies have reported that anti-MDA5 antibodies are associated with it. This study found that patients with positive anti-MDA5 antibodies are more prone to perlungual erythematosus. Therefore, it should be observed in the clinical diagnosis and treatment for patients with perlungual erythematosus. The performance of the technician hands and holster sign is relatively rare. The technician hands are mainly found in patients with anti-synthetase antibody syndrome[26] and closely related to anti-JO-1 antibody, while the holster sign refers to the outside of the buttocks or thighs rash. There are few reports on the occurrence of holster signs, because they may be misdiagnosed as other skin damage such as body lice for its occultity.

Joint swelling and pain are non-specific manifestations of connective tissue disease and can be found in a variety of connective tissue diseases, including rheumatoid arthritis, systemic lupus erythematosus, idiopathic inflammatory myopathy, and seronegative spondyloarthropathy. This study demonstrated that anti-MDA5 antibodies are associated with joint pain/swell, but the exact mechanism remains unclear.

Dyspnea, cough, and cough are the main clinical manifestations of respiratory involvement. This study displayed that anti-MDA5 antibody-positive patients are prone to dyspnea, cough symptoms, usually dry cough, no obvious cough and other discomfort, which may be associated with anti-MDA5 antibody- 
positive DM patients with ILD $[19,20]$, involving the respiratory system and causing respiratory muscle fatigue.

There is few report about anti-MDA5 antibodies that is associated with abnormal liver function. Besides liver, transaminase has other sources, including muscle, heart, kidney, and red blood cells. Studies have shown that alanine aminotransferase is relatively liver-specific, while aspartate aminotransferase lacks organ specificity and is abundant in liver, kidney, heart, muscle and other tissues, especially in myocardial and skeletal muscle. Patients with myositis can be combined with elevated transaminase. This study gave the information that anti-MDA5 antibody-positive DM patients are prone to elevated transaminase, but the specific mechanism of action is still not clear. It was discovered that the level of creatine kinase, creatine kinase isoenzyme and myoglobin is different between the two groups. However, in studies performed by Taborda[27],it was clear that the level of muscle enzyme is negatively correlated with the prognosis of patients with DM/PM. However, patients with positive anti-MDA5 antibodies have a worse prognosis, which is deferent from it.

More than half of the patients in this study had pulmonary interstitial lesions (57.80\%), and there was a significant difference in ILD and RPILD between the two groups. Patients with anti-MDA5 antibodypositive patients were more likely to suffer from ILD and RPILD. Numerous literatures[28-35] have analyzed the relationship between anti-MDA5 antibodies and ILD, and the relationship between antiMDA5 antibody and RPILD was analyzed by a number of literature[13, 14, 16, 33, 35-39], suggesting that anti-MDA5 antibody is closely related to the occurrence of ILD and RPILD. However, the mechanism of how MDA5 participates in pulmonary interstitial lesions is not clear.

Both domestic and foreign studies have reviled that it is easy for myositis to combine with tumors[40, 41], with the incidence rate of $10.9-35.8 \%$, significantly higher than the normal population, and DM is the most common one. Tumors can develop before and after the diagnosis of myositis or at the same time, and about $60 \%$ of patients suffer from tumors more than 1 year after the diagnosis of myositis[42]. Grau[43] pointed out that pulmonary interstitial lesions are negatively correlated with tumors. That means patients with pulmonary interstitial lesions should have fewer tumors. The results in this study accords with this, and patients with anti-MDA5-positive DM have fewer tumors. Further analysis to patients in this study with other myositis-specific antibodies revealed significant difference in the anti-TIF1Y antibody and antiNXP2 antibody positive between the two groups, namely, the anti-MDA5 antibody-positive group was less anti-TIF1Y antibody and anti-NXP2 antibody. Positive. Hoshino[28] reported that among 12 anti-TIF1Y antibody-positive patients, 7 patients had tumors (58\%), manifesting that anti-TIF1Y antibodies are associated with tumors in patients with myositis. According to Albayda[44], 5 patients with anti-NXP2 antibody-positive DM (9\%) had tumors, much higher than the normal population. Therefore, in recent years, anti-TIF1Y antibody and anti-NXP2 antibody were considered to be biomarkers of tumors for patients with myositis. In this study, patients were followed up for 1 year to 3 years. Some patients were not followed up for a long time, occurring missed tumor diagnosis. 
DM/PM is prone to ILD, and patients with ILD usually have a poor prognosis. Anti-MDA5 antibodies are closely related to ILD and RPILD, and most patients with anti-MDA5 antibody-positive DM have a poor prognosis. Gono[45] reported 24 patients with DM, complicated with pulmonary interstitial lesions, 14 of whom were positive for anti-MDA5 antibody, with $60 \%$ of 10 -month survival rate. Meanwhile, ferritin, antiMDA5 antibody, etc. were found, closely related to prognosis. $\mathrm{Xu}[46]$ also reported that anti-MDA5 antibody titer, skin ulcer, lymphocyte count, and ferritin are prognostic indicators for CADM patients. In this study, it was also discovered that patients with positive anti-MDA5 antibodies have a significantly increased case fatality rate and poor prognosis. Most patients with poor prognosis are associated with RPILD and may be due to respiratory failure. Therefore, for patients with first-episode DM, in order to provide further reference for future diagnosis, treatment and prognosis, the detection of myosin antibody spectrum should be actively improved. For patients with anti-MDA5-positive DM, they should be more watchful. If RPILD is combined, poor prognosis may happen at any time.

\section{Conclusion}

Combined with RP-ILD, the prognosis of IIM is poor. When patients have these clinical manifestations and positive MDA5, they must actively accept lung imaging examination and be alert to RP-ILD.

\section{Abbreviations}

IIM: idiopathic inflammatory myopathy

DM: Dermatomyositis

PM: Polymyositis

IBM: Inclusion body myositis

IMNM: Immune-mediated necrotizing myositis

ILD: Interstitial lung disease

MDA5: Melanoma differentiation-associated gene 5

CADM: Clinical amyopathic dermatomyositis

RPILD: Rapidly progressive interstitial lung disease

ALT: Alanine aminotransferase

AST: Aspartate aminotransferase

CK: Creatine kinase 
CK-MB: Creatine kinase isoenzyme

Mb: Myoglobin

TIF1y: Transcription intermediary factor 1 gamma

NXP2: Nuclear matrix protein 2

SAE1: Small ubiquitin like modifier activating enzyme heterodimer 1

SRP: Signal recognition particle

\section{Declarations}

\section{Ethics approval and consent to participate}

This study was approved by the institutional review board at Xiangya Hospital, Central South University of Changsha (Changsha, Hunan, China). The study is registered with the Clinical Trials under ID: 201903269.

\section{Consent for publication}

Not applicable.

\section{Availability of data and materials}

All data generated or analyzed during this study are included in this article.

\section{Funding}

This work was supported by the National Natural Science Foundation of China [grant numbers 81771765].

\section{Competing interests}

The authors declare that they have no competing interests.

\section{Author information}

\section{Affiliations}

Yiying Yang ${ }^{1,2,3}$, Xiaoxia Zuo ${ }^{1,3}$, Huali Zhang ${ }^{2,3}$, Hui Luo $^{1,3}$, Sijia Liu ${ }^{1,3}$

${ }^{1}$ Department of Rheumatology, Xiangya Hospital, Central South University, Changsha, Hunan 410008, China. 
${ }^{2}$ Department of Pathophysiology, Xiangya School of Medicine, Central South University, Changsha, Hunan 410008, China.

${ }^{3}$ National Clinical Research Center for Geriatric Disorders, Department of Geriatrics, Xiangya Hospital, Central South University, Changsha, Hunan 410008, China.

\section{Contributions}

YY conceived and designed the study, analyzed the data and drafted this manuscript, as the first author. $\mathrm{XZ}, \mathrm{HZ}$ and $\mathrm{HL}$ contributed to analysis of the data, and revising of the manuscript. SL designed the study and revised the manuscript. All authors have read and approved the final manuscript.

\section{Corresponding author}

Correspondence to Sijia Liu. Email: celialiu@csu.edu.cn.

\section{Acknowledgement}

This study was funded by the National Natural Science Foundation of China [grant numbers 81771765].

\section{References}

1. Dorph C, Lundberg IE: Idiopathic inflammatory myopathies - myositis. Best Pract Res Clin Rheumatol 2002, 16:817-832.

2. Askanas V, Engel WK, Mirabella M: Idiopathic inflammatory myopathies: inclusion-body myositis, polymyositis, and dermatomyositis. Curr Opin Neurol 1994, 7:448-456.

3. Acosta I, Matamala JM, Jara P, Pino F, Gallardo A, Verdugo R: [Idiopathic inflammatory myopathies. A review]. Rev Med Chil 2019, 147:342-355.

4. Bottai M, Tjarnlund A, Santoni G, Werth VP, Pilkington C, de Visser M, Alfredsson L, Amato AA, Barohn RJ, Liang MH, et al: EULAR/ACR classification criteria for adult and juvenile idiopathic inflammatory myopathies and their major subgroups: a methodology report. RMD Open 2017, 3:e000507.

5. Meyer A, Meyer N, Schaeffer M, Gottenberg JE, Geny B, Sibilia J: Incidence and prevalence of inflammatory myopathies: a systematic review. Rheumatology (Oxford) 2015, 54:50-63.

6. Oddis CV: Idiopathic inflammatory myopathy: management and prognosis. Rheum Dis Clin North Am 2002, 28:979-1001.

7. Dobloug GC, Svensson J, Lundberg IE, Holmqvist M: Mortality in idiopathic inflammatory myopathy: results from a Swedish nationwide population-based cohort study. Ann Rheum Dis 2018, 77:40-47.

8. Woo JH, Kim YJ, Kim JJ, Choi CB, Sung YK, Kim TH, Jun JB, Bae SC, Yoo DH: Mortality factors in idiopathic inflammatory myopathy: focusing on malignancy and interstitial lung disease. Mod Rheumatol 2013, 23:503-508. 
9. Furst DE, Amato AA, lorga SR, Gajria K, Fernandes AW: Epidemiology of adult idiopathic inflammatory myopathies in a U.S. managed care plan. Muscle Nerve 2012, 45:676-683.

10. Ernste FC, Reed AM: Idiopathic inflammatory myopathies: current trends in pathogenesis, clinical features, and up-to-date treatment recommendations. Mayo Clin Proc 2013, 88:83-105.

11. Venalis $\mathrm{P}$, Lundberg IE: Immune mechanisms in polymyositis and dermatomyositis and potential targets for therapy. Rheumatology (Oxford) 2014, 53:397-405.

12. Morisset J, Johnson C, Rich E, Collard HR, Lee JS: Management of Myositis-Related Interstitial Lung Disease. Chest 2016, 150:1118-1128.

13. Sato S, Hirakata M, Kuwana M, Suwa A, Inada S, Mimori T, Nishikawa T, Oddis CV, Ikeda Y: Autoantibodies to a 140-kd polypeptide, CADM-140, in Japanese patients with clinically amyopathic dermatomyositis. Arthritis Rheum 2005, 52:1571-1576.

14. Sato S, Hoshino K, Satoh T, Fujita T, Kawakami Y, Fujita T, Kuwana M: RNA helicase encoded by melanoma differentiation-associated gene 5 is a major autoantigen in patients with clinically amyopathic dermatomyositis: Association with rapidly progressive interstitial lung disease. Arthritis Rheum 2009, 60:2193-2200.

15. Wang KG, Du XM, Cheng DY: [Anti-melanoma differentiation-associated gene 5MDA5antibody and dermatomyositis with anti-MDA5 antibody]. Zhonghua Nei Ke Za Zhi 2018, 57:938-941.

16. Chen F, Wang D, Shu X, Nakashima R, Wang G: Anti-MDA5 antibody is associated with A/SIP and decreased T cells in peripheral blood and predicts poor prognosis of ILD in Chinese patients with dermatomyositis. Rheumatol Int 2012, 32:3909-3915.

17. Li L, Wang Q, Yang F, Wu C, Chen S, Wen X, Liu C, Li Y: Anti-MDA5 antibody as a potential diagnostic and prognostic biomarker in patients with dermatomyositis. Oncotarget 2017, 8:26552-26564.

18. Li J, Liu Y, Li Y, Li F, Wang K, Pan W, Meng D: Associations between anti-melanoma differentiationassociated gene 5 antibody and demographics, clinical characteristics and laboratory results of patients with dermatomyositis: A systematic meta-analysis. J Dermato/ 2018, 45:46-52.

19. Nakashima R, Hosono Y, Mimori T: Clinical significance and new detection system of autoantibodies in myositis with interstitial lung disease. Lupus 2016, 25:925-933.

20. Kawasumi H, Gono T, Kawaguchi Y, Yamanaka H: Recent Treatment of Interstitial Lung Disease with Idiopathic Inflammatory Myopathies. Clin Med Insights Circ Respir Pulm Med 2015, 9:9-17.

21. Tomimitsu H, Ohta A, Nagai M, Nishina M, Ishihara S, Kohsaka H: Epidemiologic analysis of the clinical features of Japanese patients with polymyositis and dermatomyositis. Mod Rheumatol 2016, 26:398-402.

22. Kazandjieva J, Tsankov N, Pramatarov K: The red face revisited: connective tissue disorders. Clin Dermatol 2014, 32:153-158.

23. Sun Y, Liu Y, Yan B, Shi G: Interstitial lung disease in clinically amyopathic dermatomyositis (CADM) patients: a retrospective study of 41 Chinese Han patients. Rheumatol Int 2013, 33:1295-1302. 
24. Wu H, Geng D, Xu J: An approach to the development of interstitial lung disease in dermatomyositis: a study of 230 cases in China. $J$ Int Med Res 2013, 41:493-501.

25. Narang NS, Casciola-Rosen L, Li S, Chung L, Fiorentino DF: Cutaneous ulceration in dermatomyositis: association with anti-melanoma differentiation-associated gene 5 antibodies and interstitial lung disease. Arthritis Care Res (Hoboken) 2015, 67:667-672.

26. Alsumrain M, De Giacomi F, Mirza S, Moua T: Utility of autoimmune serology testing in the assessment of uncharacterized interstitial lung disease: a large retrospective cohort review. Respir Res 2017, 18:161.

27. Taborda AL, Azevedo P, Isenberg DA: Retrospective analysis of the outcome of patients with idiopathic inflammatory myopathy: a long-term follow-up study. Clin Exp Rheumato/2014, 32:188193.

28. Hoshino K, Muro Y, Sugiura K, Tomita Y, Nakashima R, Mimori T: Anti-MDA5 and anti-TIF1-gamma antibodies have clinical significance for patients with dermatomyositis. Rheumatology (Oxford) 2010, 49:1726-1733.

29. Kang EH, Nakashima R, Mimori T, Kim J, Lee YJ, Lee EB, Song YW: Myositis autoantibodies in Korean patients with inflammatory myositis: anti-140-kDa polypeptide antibody is primarily associated with rapidly progressive interstitial lung disease independent of clinically amyopathic dermatomyositis. BMC Musculoskelet Disord 2010, 11:223.

30. Nakashima R, Imura Y, Kobayashi S, Yukawa N, Yoshifuji H, Nojima T, Kawabata D, Ohmura K, Usui T, Fujii T, et al: The RIG--like receptor IFIH1/MDA5 is a dermatomyositis-specific autoantigen identified by the anti-CADM-140 antibody. Rheumatology (Oxford) 2010, 49:433-440.

31. Fiorentino D, Chung L, Zwerner J, Rosen A, Casciola-Rosen L: The mucocutaneous and systemic phenotype of dermatomyositis patients with antibodies to MDA5 (CADM-140): a retrospective study. J Am Acad Dermatol 2011, 65:25-34.

32. Ikeda N, Takahashi K, Yamaguchi Y, Inasaka M, Kuwana M, Ikezawa Z: Analysis of dermatomyositisspecific autoantibodies and clinical characteristics in Japanese patients. J Dermato/ 2011, 38:973979.

33. Moghadam-Kia S, Oddis CV, Sato S, Kuwana M, Aggarwal R: Antimelanoma Differentiationassociated Gene 5 Antibody: Expanding the Clinical Spectrum in North American Patients with Dermatomyositis. J Rheumato/ 2017, 44:319-325.

34. Borges IBP, Silva MG, Shinjo SK: Prevalence and reactivity of anti-melanoma differentiationassociated gene 5 (anti-MDA-5) autoantibody in Brazilian patients with dermatomyositis. An Bras Dermatol 2018, 93:517-523.

35. So H, Ip RW, Wong VT, Yip RM: Analysis of anti-melanoma differentiation-associated gene $\mathbf{5}$ antibody in Hong Kong Chinese patients with idiopathic inflammatory myopathies: diagnostic utility and clinical correlations. Int J Rheum Dis 2018, 21:1076-1081.

36. Tanizawa K, Handa T, Nakashima R, Kubo T, Hosono Y, Watanabe K, Aihara K, Oga T, Chin K, Nagai S, et al: HRCT features of interstitial lung disease in dermatomyositis with anti-CADM-140 antibody. 
Respir Med 2011, 105:1380-1387.

37. Cao H, Pan M, Kang Y, Xia Q, Li X, Zhao X, Shi R, Lou J, Zhou M, Kuwana M, et al: Clinical manifestations of dermatomyositis and clinically amyopathic dermatomyositis patients with positive expression of anti-melanoma differentiation-associated gene 5 antibody. Arthritis Care Res (Hoboken) 2012, 64:1602-1610.

38. Koga T, Fujikawa K, Horai Y, Okada A, Kawashiri SY, Iwamoto N, Suzuki T, Nakashima Y, Tamai M, Arima $\mathrm{K}$, et al: The diagnostic utility of anti-melanoma differentiation-associated gene $\mathbf{5}$ antibody testing for predicting the prognosis of Japanese patients with DM. Rheumatology (Oxford) 2012, 51:1278-1284.

39. Ceribelli A, Fredi M, Taraborelli M, Cavazzana I, Tincani A, Selmi C, Chan JY, Chan EK, Satoh M, Franceschini F: Prevalence and clinical significance of anti-MDA5 antibodies in European patients with polymyositis/dermatomyositis. Clin Exp Rheumato/ 2014, 32:891-897.

40. Selva-O'Callaghan A, Ros J, Gil-Vila A, Vila-Pijoan G, Trallero-Araguas E, Pinal-Fernandez I: Malignancy and myositis, from molecular mimicry to tumor infiltrating lymphocytes. Neuromuscul Disord 2019, 29:819-825.

41. Binesh F, Sobhanardekani M, Zabihi S, Behniafard N: Proliferating Myositis: An Inflammatory Lesion often Misdiagnosed as A Malignant Tumor. Rom J Intern Med 2016, 54:243-246.

42. Levine SM: Cancer and myositis: new insights into an old association. Curr Opin Rheumato/2006, 18:620-624.

43. Grau JM, Miro O, Pedrol E, Casademont J, Masanes F, Herrero C, Haussman G, Urbano-Marquez A: Interstitial lung disease related to dermatomyositis. Comparative study with patients without lung involvement. J Rheumatol 1996, 23:1921-1926.

44. Albayda J, Pinal-Fernandez I, Huang W, Parks C, Paik J, Casciola-Rosen L, Danoff SK, Johnson C, Christopher-Stine L, Mammen AL: Antinuclear Matrix Protein 2 Autoantibodies and Edema, Muscle Disease, and Malignancy Risk in Dermatomyositis Patients. Arthritis Care Res (Hoboken) 2017, 69:1771-1776.

45. Gono T, Sato S, Kawaguchi Y, Kuwana M, Hanaoka M, Katsumata Y, Takagi K, Baba S, Okamoto Y, Ota $\mathrm{Y}$, Yamanaka $\mathrm{H}$ : Anti-MDA5 antibody, ferritin and IL-18 are useful for the evaluation of response to treatment in interstitial lung disease with anti-MDA5 antibody-positive dermatomyositis. Rheumatology (Oxford) 2012, 51:1563-1570.

46. Xu Y, Yang CS, Li YJ, Liu XD, Wang JN, Zhao Q, Xiao WG, Yang PT: Predictive factors of rapidly progressive-interstitial lung disease in patients with clinically amyopathic dermatomyositis. Clin Rheumatol 2016, 35:113-116. 